\title{
Genital tuberculosis mimicking ovarian malignancy: A series of two cases
}

\author{
Rekha Sachan, ML Patel, Malti Maurya, Pushpalata Sachan
}

\begin{abstract}
Introduction: Genital tuberculosis is a common occurrence in developing countries such as India where pulmonary tuberculosis is widespread. Case Series: We hereby discuss two interesting case reports. First case was a 34-year-old female who presented with bilateral ovarian mass with high level of serum CA-125. Second case was a 25-year-old female who presented with complaint of infertility, huge lump and pain in lower abdomen in a reproductive age, both mimic like ovarian malignancy but ultimately diagnosed as case of genital tuberculosis. Conclusion: Genital tuberculosis should be ruled out before performing any extended surgery. Both hydrosalpinx and ovarian malignancy present as bilateral adnexal masses, transabdominal ultrasonography was also non discriminative, serum CA-125 level was also elevated in both the conditions.
\end{abstract}

Keywords: Hydrosalpinx, Ovarian malignancy, Tuberculosis, Salpingotomy, Serum CA-125

Rekha Sachan ${ }^{1}$, ML Patel ${ }^{2}$, Malti Maurya ${ }^{3}$, Pushpalata Sachan ${ }^{4}$

Affiliations: ${ }^{1} \mathrm{MS}$, FICOG, Associate Professor, Department of Obstetrics \& Gynaecology, King George Medical University, (U.P.) Lucknow; ${ }^{2} \mathrm{MD}$, Assistant Professor, Department of Nephrology Unit, Medicine, KG Medical University, UP, Lucknow; ${ }^{3} \mathrm{MD}$, Lecturer, Department of Pathology, KG Medical University, Lucknow; ${ }^{4}$ Junior Resident, Department of Physiology, KG Medical University, UP.

Corresponding Author: Dr. Rekha Sachan, MS, Associate Professor, Department of Obstetrics \& Gynaecology, C-28, Sec-J, Aliganj, Near Sangam Chauraha, Lucknow, UP-226024, India; PH: +919839009290; Email: drrekhasachan@gmail.com

Received: 16 November 2012

Accepted: 01 June 2013

Published: 01 August 2013
Sachan R, Patel ML, Maurya M, Sachan P. Genital tuberculosis mimicking ovarian malignancy: A series of two cases. International Journal of Case Reports and Images 2013;4(8):401-405.

$* * * * * * * * *$

doi:10.5348/ijcri-2013-08-342-CS-1

\section{INTRODUCTION}

Genital tuberculosis is an important cause of infertility in developing countries. It is almost always acquired by hematogenous spread from extragenital sources, primary focus of genital tuberculosis is fallopian tubes causing hydrosalpinx [1]. Pelvic inflammatory disease [2] or ascending infection by Chlamydia or Gonorrhea and sometimes tubercular infection may cause distal tubal occlusion and hydrosalpinx [3]. Hydrosalpinx usually formed due to the blockage of distal portion of fallopian tube which is filled with serous or clear fluid. The blocked tube may get distended and it takes a characteristic sausage or retort like shape [4]. Its true incidence in female is not known because large proportion of patients is asymptomatic. The major presenting symptoms are infertility (45-55\%), pelvic pain (50\%), poor general health (25\%), and menstrual disturbances (20\%). The differential diagnosis includes chronic pelvic inflammation, salpingitis and malignancies [4].

\section{CASE SERIES}

Case 1: A 34-year-old female $\left(\mathrm{P}_{5}+3\right)$ with previous five vaginal deliveries followed by three successive induced abortions presented with chief complaints of low grade evening rise fever, anorexia and pain in lower abdomen for the last six months. Her previous history of menstrual cycle was uneventful. From last five to six 
months, she was suffering from severe dysmenorhea. She had her last abortion two years back.

Past history revealed that the woman had undergone laparotomy for the same complain at district hospital about three months back and abdomen was closed as such without any surgical intervention due to presence of dense adhesions between bowel, omentum and peritoneum. On general examination patient was febrile $\left(100^{\circ} \mathrm{F}\right)$, and of average built with mild pallor. Abdominal examination revealed a paramedian vertical scar with bilateral adnexal mass without tenderness. On per speculum examination cervix was hypertrophied and circumoral erosion present. Per vaginal examination revealed normal size uterus and bilateral cystic non tender adnexal masses of about $5^{-6} \mathrm{~cm}$ in size attached to uterus with restricted mobility was present. Trans abdominal ultrasonography revealed a normal size uterus with evidence of bilateral heterogenous tubo-ovarian mass of (right $41 \times 69 \mathrm{~mm}$ and left $67 \times 69 \mathrm{~mm}$ ) in size with significant free fluid in culde-sac. Culdocentesis was done and aspirated fluid, sent for AFB culture, which was negative for Mycobacterium tuberculosis. Mantoux test was $18 \times 16 \mathrm{~mm}$ in size on third day and active immunoglobulin for tuberculosis (IgM- TB) was positive. Erythrocyte sedimentation rate (ESR) was raised (34 mm/1st hr) and chest X-ray was normal (Figure 1).

Serum CA-125 was raised to $253.66 \mathrm{IU} / \mathrm{mL}$ (normal value $<35 \mathrm{IU} / \mathrm{mL}$ ), which was around eight times higher than the normal value which strongly raised suspicion about ovarian malignancy. Computed tomography (CT) scan of abdomen and PCR for the tuberculosis could not be done due to financial constraints. On the basis of clinical finding and investigation (Mantoux test and IgM-TB), she was consulted to department of pulmonary medicine and they advised category 1 antitubercular treatment as per guidelines of Revised National Tuberculosis Control Programme (RNTCP). After two months of therapy, the patient was re-evaluated and it was found that she was significantly relieved of her symptoms of fever, pain, anorexia and dysmenorrhea. However, ultrasonography did not reveal any regression in the size of the mass but free fluid was disappeared. Repeat serum CA-125 was reported $178.03 \mathrm{IU} / \mathrm{mL}$. Antitubercular treatment was continued for nine months as there was relief in symptoms and serial fall in serum CA-125 levels. The patient was planned for laparotomy for residual tuboovarian mass of size (right 36x54 mm and left 52x54 mm) after completing nine months course of antitubercular treatment (four drugs regimen for two months, isoniazid, pyrizinamide, ethambutol and rifampicin and two drugs regimen for four months rifampicin and isoniazid) and at that time serum level of CA-125 was within normal range. Total abdominal hysterectomy with bilateral salpingo-oophorectomy was performed as patient is willing for the same and not agree for further follow-up. The histopathology of residual mass did not show any evidence of tuberculosis and malignancy. This might be

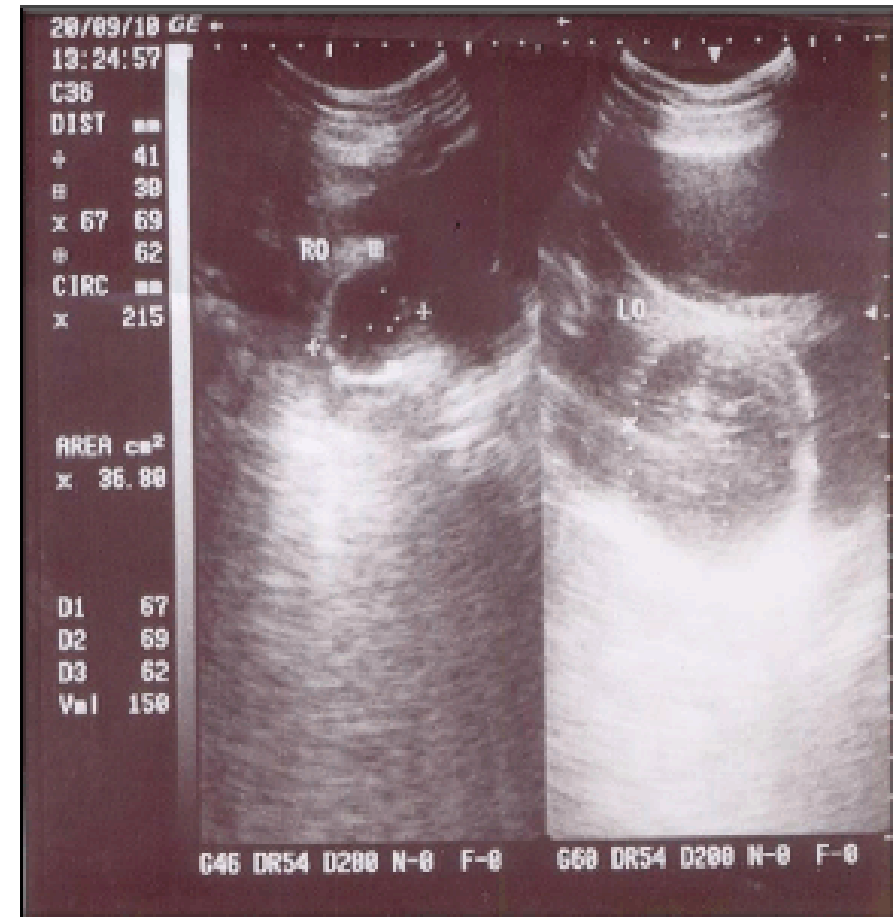

Figure 1: Ultrasonography showing bilateral heterogeneous adnexal mass.

due to patient had completed full course of antitubercular treatment. The postoperative period was uneventful. In follow-up after six weeks patient having no complained and feeling quiet well.

Case 2: A 25-year-old nulliparous infertile women referred to outpatient department with complaints of huge lump in abdomen and pain in lower abdomen since last one month, which was non radiating. She also had a history of generalized weakness. There was no history of fever and vomiting, she was married 12 months back and her menstrual cycles were of 28 to 30 days with average flow for 3 to 4 days and no accompanying dysmenorrhea.

General examination revealed moderate degree of pallor, blood pressure $120 / 70 \mathrm{mmHg}$, pulse rate 88 beats / minutes. Patient was a febrile and no lymphadenopathy present. On abdominal examination, there was a large fixed cystic lump present in the lower abdomen slightly deviated towards left measuring about $14 \times 12 \mathrm{~cm}$ in size. No abnormality was found on perspeculum examination except cervix was pulled up. On per vaginal examination about 18x12 cm size mass was felt through left fornix which was tense and cystic in consistency and non tender with restricted mobility, uterus could not be felt separately from the mass, another mass of about $8 \times 6 \mathrm{~cm}$, cystic in consistency was felt through right fornix.

Transabdominal ultrasonography revealed a large left adnexal cystic lesion measuring $185 \times 125 \times 75 \mathrm{~mm}$ in size with dense internal echoes and mural nodule with anechoic cystic structure within it, another right adnexal cystic lesion measuring $95 \times 92 \times 39 \mathrm{~mm}$ in size with septation and dense internal echoes with paraaortic (25 $\mathrm{mm}$ and $19 \mathrm{~mm}$ ) and iliac lymphadenopathy (39 $\mathrm{mm}$ and 
$19 \mathrm{~mm}$ size). All laboratory values were within normal limits except serum CA-125 was raised $(92.38 \mathrm{U} / \mathrm{mL})$, chest X-ray was unremarkable. A strong suspicion of ovarian malignancy was raised because of raised serum CA-125 along with lymphadenopathy.

An exploratory laparotomy was performed after arrangement of one unit packed red blood cells. Peroperatively a huge hydrosalpinx on left side adhered to omentum with flimsy adhesions to the bowel and peritoneum, on aspiration caseous material was found whereas right sided hydrosalpinx smaller than left was present, uterus and bilateral ovaries were normal (Figures 2-4). Right sided salpingotomy and left sided salpingectomy with adhesiolysis was done. Tissue was sent for histopathological examination. Sections from fallopian tube shows blunt and fused plicae infiltrated with mixed inflammatory infiltrate and well formed granulomas comprising lymphocytes, plasma cells, epithelioid cells and Langhans giant cells were present, suggestive of tubercular salpingitis (Figure 5 and 6). Peritoneal washing and aspirated fluid from cyst was sent for cytological and biochemical analysis. Aspirated fluid biochemical analysis showed protein $2.2 \mathrm{~g} / \mathrm{dL}$ and sugar $8 \mathrm{mg} / \mathrm{dL}$. So antitubercular treatment was given for six months according to RNTCP (four drug regimen for 2 months and 2 Drug the regimen for four month) along with anti-inflammatory treatment, during follow-up patient was asymptomatic.

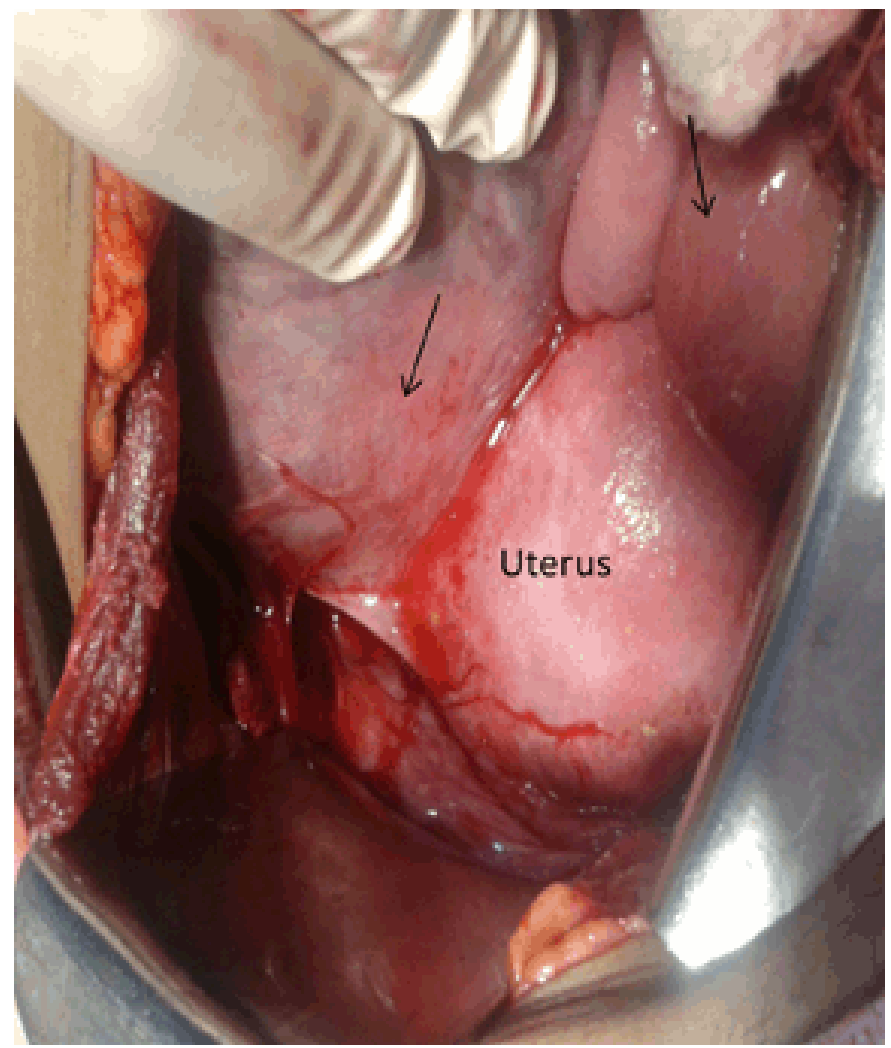

Figure 2: Peroperative finding (arrow) showing bilateral hydrosalpinx with normal size uterus.

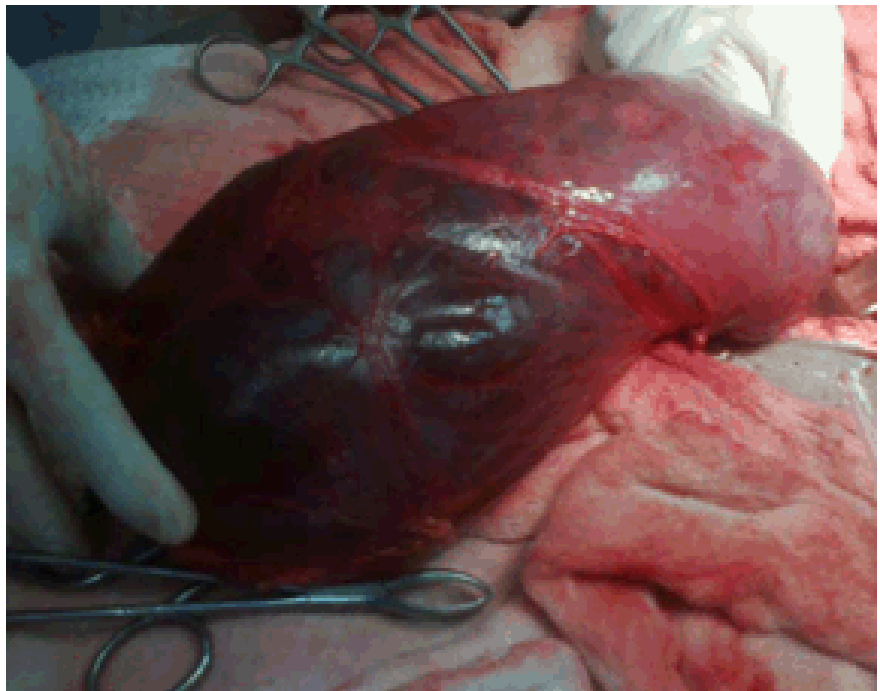

Figure 3: Left sided hydrosalpinx.

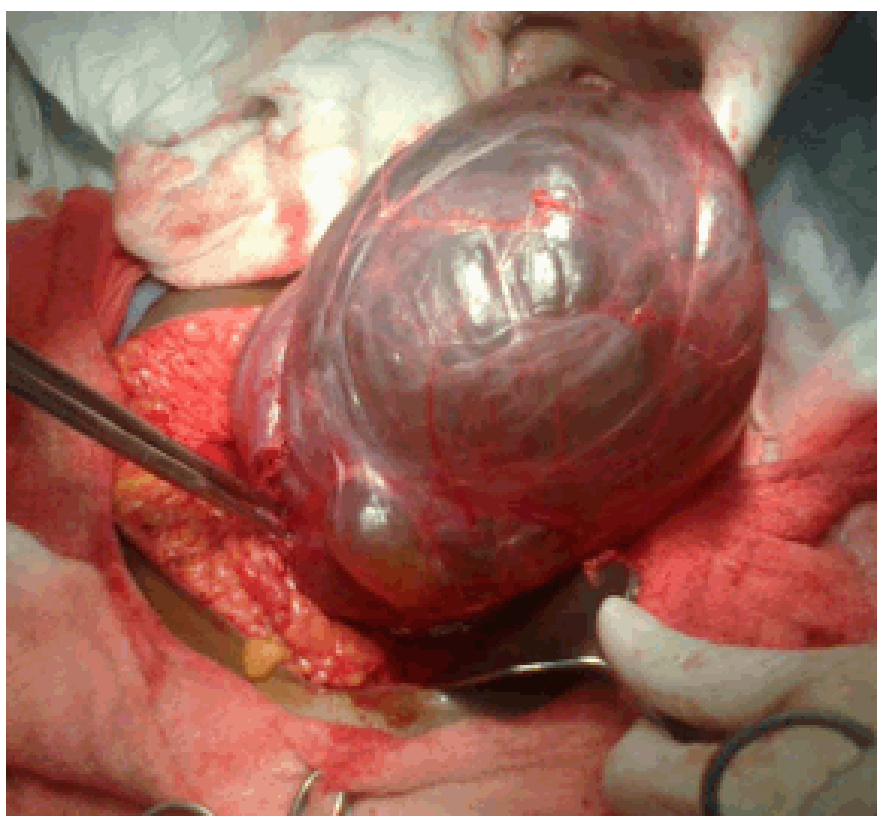

Figure 4: Right sided hydrosalpinx.

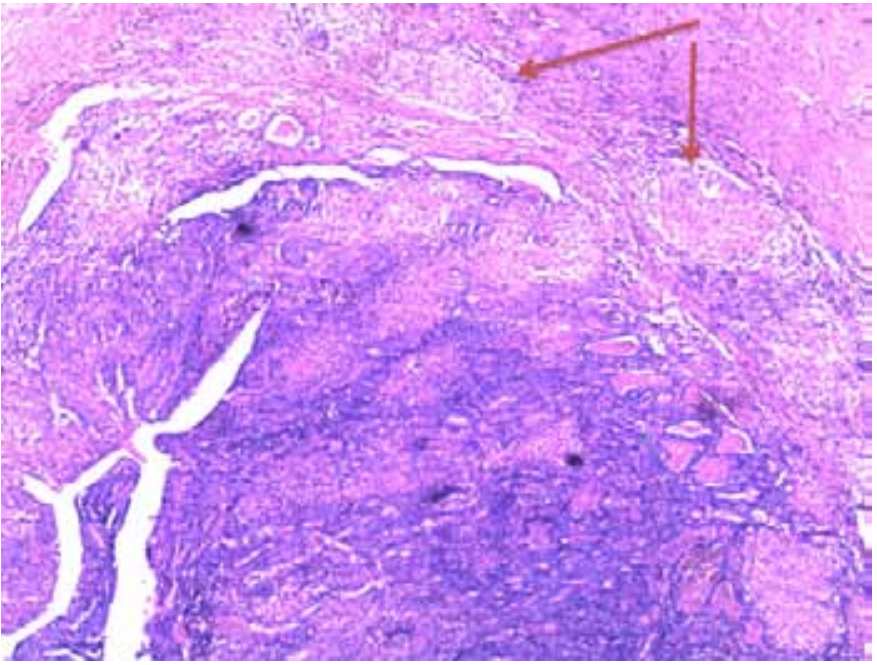

Figure 5: Wall of fallopian tube showing dense chronic inflammatory infiltrate with fused plicae (black arrow) and multiple granulomas (red arrow) (H \&E stain, x100). 


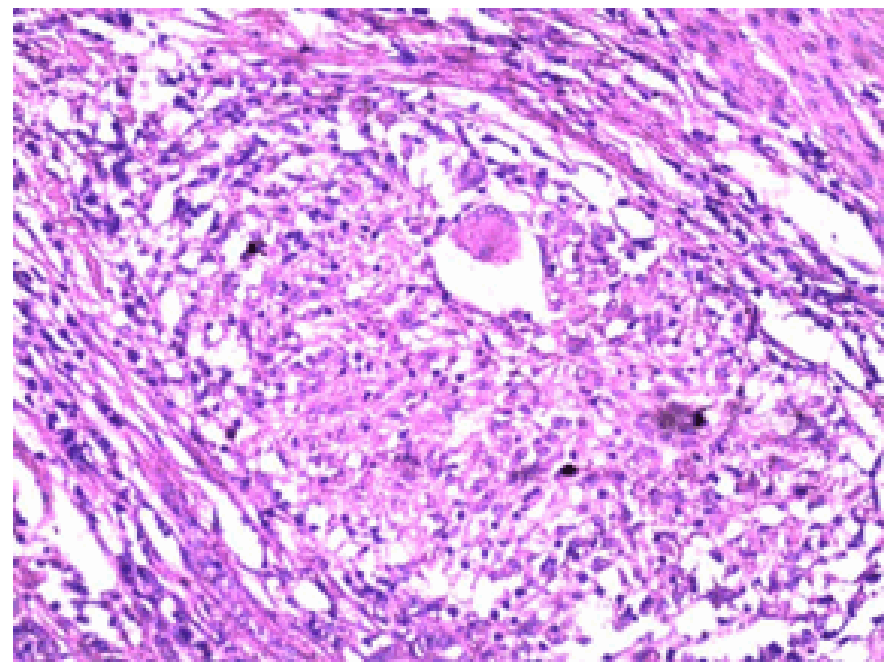

Figure 6: Granuloma showing langhans giant cell epitheloid cells and lymphocytetes (H\&E stain, x200).

\section{DISCUSSION}

Genital tuberculosis may present like ovarian malignancy with elevated serum CA-125 level. For this reason its presence should be ruled out in women presenting with adnexal masses inspite of high levels of serum CA-125 as reported in case one, similar case reported by Manidakis et al. where a case of suspected ovarian malignancy underwent laparotomy, histopathology showed features of typical genital tuberculosis [5]. Ultrasonography did not show any improvements after two months of starting therapy which means that follow-up with ultrasound may not be a very useful tool for evaluation of genital tuberculosis. Serum CA-125 values were falling rapidly after starting antitubercular treatment, which suggests that serum CA125 may be a useful marker for monitoring and follow-up of genital tuberculosis. Similar conclusion was made by Belgin $\mathrm{T}$ et al. in the study who concluded that this marker may be useful for follow-up of patients with genital tuberculosis [6]. Koc et al. also concluded that ascites and high levels of serum CA-125 do not necessarily indicate malignancy in women of reproductive age group [7]. Awareness about peritoneal tuberculosis is still lacking and many women with this disease are initially thought to have ovarian malignancy and undergo unnecessary extended surgery. Similar, past history was present in our case. After the antitubercular treatment total abdominal hysterectomy with bilateral salpingo-oophorectomy was done for residual mass because there was no reduction in the size of mass and no any investigation confirmatory for the tuberculosis, so patient is insisting for the same. Though laparoscopy and guided biopsy to be a sufficient and safe method to provide diagnosis of peritoneal tuberculosis but it was not done as previous record of laparotomy showing dense adhesions [8].

Tubercular hydrosalpinx are almost always bilateral but not symmetrical in size and shape. Tubes are thickened and show a rough external surface with adhesion, caseous ulceration of mucosa produces ragged contours and diverticular out pouching of both isthmus and ampulla, similarly reported in Case 2.

As tuberculosis heals, the entire tube become encased in heavy connective scar tissue and the lumen develops a beaded rigid stem pipe appearance [9]. The most common site of obstruction is the region of transition between isthmus and ampulla [10]. Hydrosalpinx may be asymptomatic, when it is bilateral, women may be infertile as reported in this case. Other causes of distal tubal occlusion include adhesion formation from surgery and endometriosis. Some patients have recurring lower abdominal pain while others are asymptomatic. Our case also presented with lower abdominal pain.

Generally, treatment for hydrosalpinx is either salpingotomy or salpingectomy so we did left sided salpingectomy and right sided, salpingotomy because our patient was nulliparous [11]. After histopathological examination, it was diagnosed as tubercular salpingitis so antitubercular treatment was given for six months along with anti-inflammatory treatment. Although hydrosalpinx is very uncommon in developed countries but in developing countries still the tuberculosis is important etiological factor responsible for the development of hydrosalpinx [12].

\section{CONCLUSION}

This case series demonstrate a high rate of misdiagnosis between advanced ovarian malignancy and genital tuberculosis. Genital tuberculosis should be ruled out before performing any extended surgery. Both hydrosalpinx and ovarian malignancy present as bilateral adnexal masses, transabdominal ultrasonography was also non discriminative, serum CA-125 level was also elevated in both conditions. Whereas abdominal paracentesis is useless in ruling out genital tuberculosis and serum CA-125 levels, may be useful in follow-up of patients.

\section{$* * * * * * * * *$}

\section{Author Contributions}

Rekha Sachan - Substantial contributions to conception and design, Drafting the article, Fnal approval of the version to be published

ML Patel - Analysis and interpretation of data, Final approval of the version to be published

Malti Maurya - Acquisition of data, Final approval of the version to be published

Pushpalata Sachan - Drafting the article, Final approval of the version to be published

\section{Guarantor}

The corresponding author is the guarantor of submission. 


\section{Conflict of Interest}

Authors declare no conflict of interest.

\section{Copyright}

(C) Rekha Sachan et al. 2013; This article is distributed under the terms of Creative Commons attribution 3.0 License which permits unrestricted use, distribution and reproduction in any means provided the original authors and original publisher are properly credited. (Please see www.ijcasereportsandimages.com/copyright-policy.php for more information.)

\section{REFERENCES}

1. Schwimmer M. Gynecological inflammatory diseases. In: Pollack HM, editor. Clinical urography (1st edn) Philadelphia: W.B. Saunders, 1990:985-6.

2. Morse AN, Schroeder CB, Magrina JF et al. The risk of hydrosalpinx formation and adnexectomy following tubal ligation and subsequent hysterectomy. Am J Obstet Gynecol. 2006;194(5):1273-6.

3. Gomel V, Taylor E. Reconstructive tubal surgery. In Te Linde's Operative Gynaecology, eds. Rock JA, Jones HW III. 10th Edition, New Delhi 2008,pp. 403420.

4. Chowdhury NN. Overview of tuberculosis of the female genital tract. J Indian Med Assoc. 1996, Sep; 94(9):345-6, 361.
5. Manidakis LG, Angelakis E, et al. Genital tuberculosis can present as disseminated ovarian carcinoma with ascites and raised CA125: A case report. Gynecol Obstet Invest. 2001;51(4):277-9.

6. Bilgin T, Karabay A, Dolar E, Develioglu OH. Peritoneal tuberculosis with pelvic abdominal mass, ascites and elevated CA 125 mimicking advanced ovarian carcinoma: A series of 10 cases. Int J Gynecol Cancer. 2001 Jul-Aug;11(4):290-4.

7. Koc S, Beydilli G, Tulunay G, Ocalan R, Boran $\mathrm{N}$, Ozgul N, Kose MF, Erdogan Z. Peritoneal tuberculosis mimicking advanced ovarian cancer: A retrospective review of 22 cases. Gynecol Oncol. 2006 Nov;103(2):565-9.

8. Piura B, Rabinovich A, Leron E, Yanai-Inbar I, Mazor M.. Peritoneal tuberculosis--an uncommon disease that may deceive the gynecologist. Eur $\mathrm{J}$ Obstet Gynecol Reprod Biol. 2003 Oct 10;110(2):230-4.

9. Yoder IC. Hysterosalpingography and pelvic ultrasound: imaging in infertility and gynecology (1st edn). Boston: Little Brown and Company, 1988:66-9.

10. Klein TA, Richmond JA, Mishell DR. Pelvic tuberculosis Obstet Gynecol 1976;48:99-104.

11. Taylor RC, Berkowit CH, McComb PF. Role of laparoscopic salpingostomy in the treatment of hydrosalpinx. Fertil Steril 2001;75: 594-600.

12. Merchant SA. Genital tract tuberculosis. In: Subbarao $\mathrm{K}$, Banerjee S, editors. Diagnostic radiology and imaging (1st edn). New Delhi: Jaypee Brothers, 1997:637-46.
Access full text article on other devices

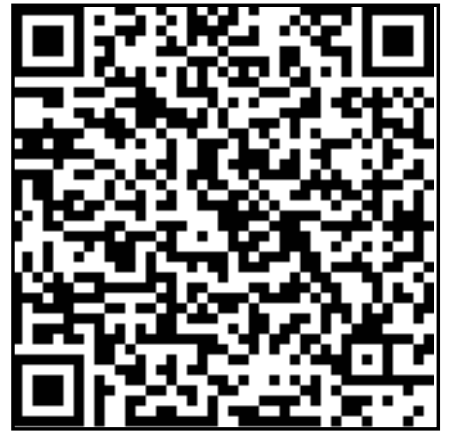

Access PDF of article on other devices

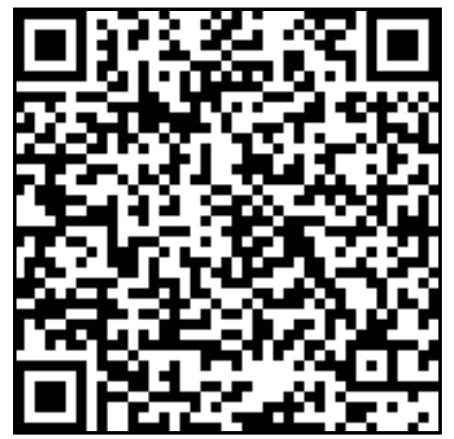

